\title{
Guilt- and Shame-Proneness and Their Relation to Perceptions of Dating Infidelity
}

\author{
Adriana Kaplánová \\ Department of Sport Educology and Sport Humanities \\ Faculty of Physical Education and Sport \\ Comenius University, Bratislava
}

\author{
Alexander Gregor \\ Department of Psychology \\ Faculty of Philosophy and Arts \\ Trnava University, Trnava
}

\begin{abstract}
This paper explores how proneness to guilt and shame is related to perceptions of dating infidelity. Research data was collected from 805 participants from Slovakia. Attitudes toward extradyadic behaviors were measured by the Perceptions of Dating Infidelity Scale. Guilt- and shame-proneness were assessed by the Guilt and Shame Proneness Scale (GASP). Results indicated that guilt- and partially shame-proneness were associated with less permissive perceptions of dating infidelity. A moderating effect of age was found in both subscales of guilt-proneness and perceptions of sexual infidelity. Gender moderated the association between perceptions of deceptive behavior and negative self-evaluations of shame-proneness, such that this association was positive for women and negative for men.
\end{abstract}

Key words: guilt- and shame-proneness, infidelity, attitudes, perceptions of dating infidelity

\section{Introduction}

Infidelity has been traditionally regarded as a topic of interest for both researchers and laypeople, and it has been a hot topic in romantic relationships, given its hurtful nature. According to a large study carried out by Widmer

\section{Acknowledgments}

With special regard, we would like to thank Professor Peter Halama for consulting assistance during the preparation of this paper.

Correspondence concerning this article should be addressed to Mgr. et Mgr. Adriana Kaplánová, Department of Sport Educology and Sport Humanities, Faculty of Physical Education and Sport, Comenius University, Nábrežie armádneho generála Ludvíka Svobodu 42e98/9, 814 69, Bratislava, Slovak Republic. E-mail: kaplanova8@uniba.sk

Received November 4, 2018 and Tras (1998), proneness towards infidelity as reflected upon sexual attitudes has been found to be strikingly high among Western European countries (Sweden, Norway, Finland, the Netherlands, West Germany, and France). Besides Western European trends, infidelity is reputed to be strikingly high in Thailand and large parts of South America (Schmitt et al., 2004).

Infidelity (colloquially, cheating) most commonly assumes a breach of sexual agreement. According to Berman and Frazier (2005), infidelity is a sexual or romantic involvement with someone other than one's primary partner, which is concealed from the partner, because it would be unacceptable to him/her. Researchers deal with two kinds of infidelity - sexual and emotional. Sexual infidelity is considered as engaging in sexual intercourse with somebody other than one's partner, whereas emotional infidelity is considered as "falling in love" or sharing 
a deep emotional bond with someone other than one's partner (Whitty \& Quigley, 2008). There is some overlap between the two, as sexual infidelity may involve emotional involvement and vice versa.

A key-defining characteristic of a monogamous relationship is that, typically, certain behaviors are considered as acceptable only for the two individuals involved in the relationship. (Luo, Cartun, \& Snider, 2010). When an individual engages in such exclusive behaviors with someone outside the primary relationship without their partner's consent, such behaviors are termed extradyadic (e.g., Luo, Cartun, \& Snider, 2010). These may comprise diverse behaviors including deep kissing/tongue kissing," oral contact with nipples, oral sex with or without orgasm, and masturbation to orgasm in the presence of another person. (Randall \& Byers, 2003). Thus, its operationalization and measurement has been miscellaneous across studies (Blow \& Hartnett, 2005). Moreover, research has shown that there are inconsistencies in individuals' perceptions of which non-sexual behaviors are indicative of cheating (Wilson, Mattingly, Clark, Weidler, \& Bequette, 2011). Cheating is often associated with extradyadic types of behavior that usually serve as a means of attracting another sexual partner. Although extradyadic forms of behavior do not necessarily mean that an individual wants to cheat, they usually reflect a certain propensity for cheating. Infidelity is the final result of extradyadic behaviors which commonly undermines the trust between partners and leads to the termination of the relationship. In our study, we abide by the taxonomy of different behaviors developed by Wilson et al. (2011) - authors of the Perceptions of Dating Infidelity Scale (PDIS) which clearly defines all three types of extradyadic behaviors: as deceptive, ambiguous, and explicit. Permissive attitudes towards extradyadic behaviors are understood as a general indication for the tendency toward infidel- ity (Wilson et al., 2011). Moreover, Hackathorn, Mattingly, Clark, and Mattingly (2011) found that PDIS-ambiguous scores predicted the likelihood of engaging in similar behaviors over a one-month follow-up. Presently, there are three recognized factors that predict more permissive attitudes toward infidelity - the history of infidelity, age, and staying in a romantic relationship for a longer period of time (Toplu-Demirtas \& Fincham, 2017; Silva, Saraiva, Albuquerque, \& Arantes, 2017).

Shame as a psychological construct is a primary self-conscious emotion. In recent decades, it has been investigated mostly in social and personality psychology. More recently and in a cumulative rate, shame has been researched in a domain of clinical psychology and psychopathology. From the phenomenological perspective, feelings of shame are most closely connected with failure, embarrassment, estrangement, vulnerability, worthlessness, hopelessness, and personal inadequacy, and split within self-structure arising during unpleasant social situations (Ramsey, 1988; Wheeler, 1997). Regarding intimate relationships, shame is connected with unsatisfied body image, sexual inadequacy, sexual activity outside of the romantic relationship, abandonment by the intimate partner, and being a victim of intimate violence or violence perpetration (O'Sullivan \& MeyerBahlburg, 2003; Gruber, Hansen, Soaper, \& Kivisto, 2014).

Guilt is often explored in psychological research as a covariate alongside shame. Baumeister, Stillwell, and Heatherton (1994) define guilt as a subjectively unpleasant emotional state, linked with objections towards one's own actions, deeds, circumstances, or intentions. Guilt is understood as an adaptive emotion based on an individual's own negative evaluation of his/her behavior and actions (Gilbert, 2001). Guilt motivates an individual toward reparative actions of previous behavior, considered wrong by them, others, or social norms. 
Shame and guilt are related to infidelity through many aspects. For instance, the direct disclosure of an affair from an unfaithful partner is hard to make, due to the anticipation of unwanted feelings associated with shame (Allen, 2018). Furthermore, presenting a cheating partner with the evidence of his/her infidelity makes one feel shame as well (Allen, 2018). In such situations, the feeling of shame relates primarily to one's Self, as one is aware that exposing himself/herself to the partner makes him/ her uncomfortable. Besides, when experiencing betrayal shame usually occurs on the part of the betrayed partner. Rejection felt by a betrayed partner will usually result in feelings of inadequacy or unattractiveness and probably give rise to shame.

The pattern of guilt entangled with infidelity is, however, different. Guilt should be a primary consequence of extradyadic behavior, since unfaithful individuals will likely perceive themselves as breaking a prior commitment or social contract (Fisher, Voracek, Rekkas, \& Cox, 2008). Oftentimes, feelings of guilt in the unfaithful partner arise as an outcome of seeing how hurt the other partner is. Thus, guilt differs from shame, in the sense that the attention resulting from guilt is directed at the partner and possible reparation of infidelity is sought. The resulting aversive emotional state arising from guilt may cause infidelity to be regarded as an objectionable social transgression, making it unappealing and less likely to be repeated (Fisher et al., 2008). However, the experience of guilt does not appear to depend on the partner's knowledge of the infidelity (Spanier \& Margolis, 1983). Mongeau, Hale, and Alles (1994) found that the more intentional the infidelity, the less guilt the cheaters feel; thus, the degree of experiencing guilt over infidelity is inversely related to the intention of infidelity. However, only one study has been conducted about guilt and perceptions of dating infidelity. Wilson et al. (2011) found that participants who perceived the set of extradyadic behaviors as cheating were significantly more likely to indicate feeling greater guilt regarding hypothetical cheating scenarios.

A crucial point of our theoretical model is justifying how guilt- and shame-proneness can predict perceptions of dating infidelity. We contemplate how guilt-proneness may predict less permissive perceptions of dating infidelity through links with several personality variables. First, guilt-proneness was found to be the strongest predictor of trustworthiness (Levine, Bitterly, Cohen, \& Schweitzer, 2018); it has been correlated with honesty-humility around .50 , indicating that people low in guiltproneness are generally dishonest (Cohen, Panter, \& Turan, 2012b). Second, guilt-proneness is modestly related to conscientiousness and agreeableness, stressing that people low in guilt-proneness tend to be more unreliable than high guilt-prone persons (Cohen, Panter, \& Turan, 2012b). Trustworthy people feel greater responsibility for the well-being of others and are more authentic and honest. Cheaters often blame victims for causing their infidelity and since they violate trustworthiness within a relationship, they may be perceived as untrustworthy and dishonest (Weeks, Fife, $\&$ Peterson, 2016). Such persons may develop more permissive perceptions of dating infidelity, since their behavior within intimate relationships may encompass overt or hidden signs of less predictability, honesty, and reliability, which may give rise to infidelity. Additionally, individuals low in honesty-humility were found to be susceptible to commit infidelity, since they are willing to act against relationship rules to fulfil their personal desires, acting as a motivator (Carmody \& Gordon, 2011; McKibbin, Miner, Shackelford, Ehrke, \& Weekes- Shackelford, 2014; Lee et al., 2013). Alternately, highly agreeable and conscientious individuals may imply lesser incentives for infidelity, since they have more persever- 
ance in intimate relationships, regardless of conflicts, and are better at resisting seduction (Barta \& Kiene, 2005; Jonason, Teicher, \& Schmitt, 2011). Moreover, Shackelford, Besser, and Goetz (2008) reasoned that less agreeable and conscientious individuals are less satisfied in their marriage, resulting in higher likelihood of infidelity.

Based on the attachment perspective, we scrutinize why shame-proneness appears to be a possible predictor of perceptions of dating infidelity. According to Mikulincer and Shaver (2007), a child's intense shame experience in close relationships may impact working models and thus possibly affect later intimate relationships. Research shows that adult shameprone individuals are more likely to be characterized with higher attachment anxiety, as there exists broader evidence supporting a link between adult attachment anxiety and shameproneness (Lopez et al., 1997; Gross \& Hansen, 2000; Wei, Shaffer, Young, \& Zakalik, 2005; Heflin, 2015). Individuals with higher attachment anxiety are more likely to desire constant and long-term relationships (Davis, Shaver, \& Vernon, 2004); they tend to experience separation from their partner in a harsher way (Fraley \& Shaver, 1998); being more sensitive to relationship threats, they are likely to have less permissive attitudes toward infidelity (Kruger et al., 2013). Some research shows that attachment anxiety is related to (Ong, Poon, Sibya, \& Macapagal, 2014) or predicts less permissive attitudes toward infidelity (Kruger et al., 2013; Stewart, 2017). According to Stewart (2017), some behaviors presented in the Perceptions of Dating Infidelity Scale may be perceived as more indicative of infidelity for anxiously attached individuals, because they represent possible instability, abandonment, and rejection on the part of the committed partner. Thus, attachment anxiety, related to the fear of losing one's partner, appears to confer a somewhat greater sensitivity in reaching the perception that a person's fidelity is in question (Kruger et al., 2013). Alternately, heightened sensitivity to threats and rejection is just one characteristic mechanism of shame-prone people (Dickerson, Gruenewald, \& Kemeny, 2009); hence, it seems to be the best-fitting parallel between shame-proneness and attachment anxiety. Since shame-prone individuals characterized with higher attachment anxiety are more sensitive to social cues representing a perceived threat for their relationships, they are likely to perceive extradyadic behaviors as cheating and, thus, their perceptions of dating infidelity are more likely to be less permissive. In fact, this appears to be the best reasoning why shame-proneness may predict less permissive perceptions of dating infidelity.

Despite up-to-date, strong evidence that men engage in sexual infidelity more than women (Tafoya \& Spitzberg 2007; Labrecque \& Whisman, 2017), no gender differences were actually found across studies in perceptions of sexual infidelity as measured by PDIS (Mattingly, Wilson, Clark, Bequette, \& Weidler, 2010; Hackathorn et al., 2011; Wilson et al., 2011; Silva et al., 2017). These studies found that women rated ambiguous behaviors as more indicative of cheating than men. More distinct are gender differences in guilt-proneness, as women were found to be more guiltprone than men (Cohen, Wolf, Panter, \& Insko, 2011; Cohen, Panter, \& Turan, 2012a; Cohen, Panter, Turan, \& Morse, 2012). Concerning shame-proneness, only shame negative selfevaluations were detected to be more prominent in women (Cohen et al., 2011). Based on these studies, we examined gender as a moderator as well.

Similar to gender, age may be expected to be a moderator. The General Social Survey 20002016 in the USA showed that with increasing age, the frequency of extramarital sex increases and reaches a peak at 60 (Wolfinger, 2017). Furthermore, Silva et al. (2017) found a modest as- 
sociation between permissiveness of attitudes toward infidelity and age. However, regarding perceptions of dating infidelity, these authors found that only permissive perceptions of sexual infidelity correlated with age. Contrary to this finding, Cuñas \& Koval (2018) found permissive perceptions of only emotional infidelity to increase significantly with age.

Concerning guilt-proneness, age differences are well documented across various studies indicating that guilt-proneness increases with age (Orth, Robins, \& Soto, 2010; Tangney, Stuewig, Mashek, \& Hastings, 2011; Cohen et al., 2011). Less clear are the age differences in shameproneness. Orth, Robins, and Soto (2010) found shame-proneness decreases with age, even though other studies indicate that the overall shame-proneness is unrelated to age (Tangney et al., 2011; Orth, Robins, \& Soto, 2010). Therefore, age is more likely to moderate the association between guilt-proneness and perceptions of sexual infidelity in our study.

Our study has three aims. First, it tests the hypothesis of an existing positive significant relationship between guilt-proneness and less permissive perceptions of both sexual and emotional infidelity. Second, it tests whether there exists a significant relationship between shameproneness and permissive perceptions of dating infidelity. Third, it tries to detect if age and gender moderate any of these possible significant relationships.

\section{Method}

\section{Participants}

The data was gathered from a sample of 805 participants from Slovakia: 271 males (34\%) and 534 females $(66 \%)$; their mean age was 28.1 years $(S D=8.74$, range 18-83). In most cases, participants were sent an appeal through Facebook messenger to fill out the questionnaire. Other responses were collected by placing the ques- tionnaire in well-visited Facebook groups. Additionally, a small number of participants directly asked to respond via email to participate in our study. The data was acquired in May and June 2018.

\section{Measures}

The following scales used were freely available without the need for permission from the original authors. Both scales were double translated to preserve the intact meaning of all items. To measure attitudes towards sexual and emotional infidelity, we administered the Perceptions of Dating Infidelity Scale (PDIS) (Wilson et al., 2011). This assesses the degree to which specific behaviors are considered infidelity. It consists of 12 Likert-type scaled items $(0=$ never cheating to $6=$ always cheating). It has three subscales (factors) designated as ambiguous (e.g., "Talking by phone or internet with someone other than your partner"), deceptive (e.g., "Lying to your partner"), and explicit (e.g., "Giving and/or receiving oral sex with someone other than your partner"). The individual score is assessed on the basis of the average of each of the subscales separately. Ambiguous behaviors are those in which the individual's motivations seem unclear but may be benign. Deceptive behaviors are those in which the individual's behaviors are mainly internal or hidden and assist in deceiving one's partner. Explicit behaviors are those where the individual clearly breaks the agreement of monogamy by engaging in sexual behaviors with someone other than his/ her romantic partner. The explicit subscale is supposed to measure the perceptions of sexual infidelity, whereas the ambiguous and deceptive subscales measure perceptions of emotional infidelity. The PDIS thus reflects individual attitudes toward extradyadic behaviors. On the individual level, this set of behaviors may be considered from harmless to disruptive for intimate relationships, and a lower score indicates 
permissive attitudes toward extradyadic behaviors. Original Cronbach coefficient alphas are $\alpha=.83 ; .72 ; .81$ for explicit, deceptive, and ambiguous behavior, respectively. In this study, the internal consistency of PDIS reached the following values: ambiguous $\alpha=.89$; deceptive $\alpha=.67$, and explicit $\alpha=.89$.

To assess the individual degree of guilt- and shame-proneness, we used the Guilt and Shame Proneness Scale-GASP (Cohen et al., 2011), an inventory based on tenets of another test called Test of Self Conscious Affect TOSCA (Tangney \& Dearing, 2002). GASP is a scale consisting of four subscales: Guilt Negative Behaviour Evaluations (GNBE), Guilt-Repair (GR), Shame Negative Self-Evaluations (SNSE), and Shame-Withdraw (SW). Respondents are required to imagine themselves in situations where they have committed personal transgression and then asked to mark the likelihood they would act or feel in the way described. GASP consists of 16 items ranked on a seven point Likert-type scale: from 1 (very unlikely) to 7 (very likely). Guilt-NBE items describe feeling bad about how the respondent acted (e.g., "You would feel that the way you acted was pathetic."). They describe action tendencies (i.e., behavior or behavioral intentions) focused on correcting or compensating for the transgression (e.g., "You would try to act more considerately toward your friends."). Shame-NSE items describe feeling bad about oneself (e.g., "You would feel like a bad person."). Shame-withdraw items describe action tendencies focused on hiding or withdrawing from public (e.g., "You would avoid the guests until they leave."). The benchmark on the test quality parameter is established on .60 of each subscale (Cohen et al., 2011). In this study, the internal consistency of GASP reached the following values: guilt-negative behavior evaluation $\alpha=.71$; guilt-repair $\alpha=$ .67 ; shame-negative-self-evaluation $\alpha=.65$, and shame-withdraw $\alpha=.65$. These values are almost identical to the values found by Cohen et al. (2011) in their second study.

\section{Results}

The data was analyzed using IBM SPSS Statistics. We used the correlational research design to assess the proximity of relationships between guilt- and shame-proneness and perceptions of dating infidelity. The proximity of the relationship was assessed for $5 \%$ and $1 \%$ levels of statistical significance. Analysis of results and descriptive characteristics are pre-

Table 1 List of study variables with their possible score ranges, mean scores, standard deviations, and correlation matrix of the variables of perceptions of dating infidelity, guilt-and shame-proneness

\begin{tabular}{lrrlllllll}
\hline Variable & Mean & SD & AMB & DCP & EXP & NBE & GR & NSE & SW \\
\hline AMB (0-36) & 16.3 & 9.23 & & & & & & & \\
DCP (0-12) & 6.5 & 3.09 & $\mathbf{. 3 5} * *$ & & & & & \\
EXP (0-24) & 23.0 & 2.99 & $\mathbf{. 3 5} * *$ & $\mathbf{. 2 5} * *$ & & & & \\
NBE (4-28) & 22.3 & 5.17 & $\mathbf{. 1 2} * *$ & $\mathbf{. 2 4} * *$ & $\mathbf{. 1 4} * *$ & & & \\
GR (4-28) & 21.3 & 4.41 & $\mathbf{. 1 2} * *$ & $\mathbf{. 2 0} * *$ & $\mathbf{. 1 4} * *$ & $\mathbf{. 5 1} * *$ & & & \\
NSE (4-28) & 23.5 & 4.78 & $\mathbf{. 1 5} * *$ & $\mathbf{. 1 4} * *$ & $\mathbf{. 1 5 * *}$ & $\mathbf{. 5 0} * *$ & $\mathbf{. 5 1 * *}$ & & \\
SW (4-28) & 11.7 & 4.70 & $\mathbf{. 2 2} * *$ & $\mathbf{. 1 2} * *$ & -.07 & -.05 & -.04 & .06 & \\
\hline
\end{tabular}

Note. AMB - Ambiguous, DCP - Deceptive, EXP - Explicit, NBE - Negative BehaviorEvaluation, GR - Guilt-Repair, NSE - Negative Self-Evaluation, SW - Shame-Withdraw. $* * p \leq .01, * p \leq .05$. 
sented in Table 1, which shows perceptions of dating infidelity having significant positive correlations with guilt- and shame-proneness.

We conducted moderation analysis, focusing on the moderation role of age and gender in the relationship between perceptions of dating infidelity and guilt- and shame-proneness. The moderation effect was estimated using Process 3.1 developed by Hayes (2018).

The computational macro for path analysis is based on moderation providing coefficient estimations using ordinary least squares regression for continuous variables. The results of the moderation analysis are presented in Table 2.

Twenty-four analyses were carried out. To reduce the chances of obtaining false-positive results (type I errors), a Bonferroni correction was additionally conducted. The Bonferroni correction is used to reduce the chances of obtaining false-positive results (type I errors) when multiple pairwise tests are performed on a single set of data (Bland \& Altman, 1995). In Table 2, we presented only the significant results. Models 1 to 3 included perceptions of dating infidelity as the outcome variable with gender or age as the moderators. The moderation effect of age was found to be significant in the subscale explicit of perceptions of dating infidelity and guilt-proneness, including negative behavior-evaluation $(F(3,801)=23.05$, $\left.p<0.01, R^{2}=0.080\right)$ and guilt-repair $(F(3,801)=$ $\left.21.83 p<0.01, R^{2}=0.076\right)$. The moderation effect of gender was detected as significant between the subscale deceptive of perceptions of dating infidelity and negative self-evaluations of shame proneness $(F(3,207)=5.17, p<0.05$, $R^{2}=0.070$ ). Moderation effect of age in the relationship between the subscale explicit and guiltproneness is graphically presented in Figure 1. Moderation effect of gender in the relationship between subscale deceptive and negative selfevaluations is also graphically presented in Figure 2 .

Table 2 Results of moderation analysis with perceptions of dating infidelity as the outcome variable, guilt-and shame-proneness as predictor variables, gender and age as moderators

\begin{tabular}{|c|c|c|c|c|c|}
\hline Predictors & Coeff & SE & $\begin{array}{l}95 \% \text { confidence } \\
\text { intervals }\end{array}$ & $\begin{array}{c}\text { R-square } \\
\text { whole } \\
\text { model } \\
\end{array}$ & $\begin{array}{c}\text { R-square } \\
\text { increase due to } \\
\text { interaction }\end{array}$ \\
\hline \multicolumn{6}{|c|}{ Model 1 - perceptions of dating infidelity as dependent variable } \\
\hline NBE & -0.140 & 0.064 & $(-0.256,-0.006)$ & \multirow{3}{*}{0.080} & \multirow{3}{*}{$0.001 * *$} \\
\hline AGE & -0.065 & 0.013 & $(-0.090,-0.040)$ & & \\
\hline EXP x NBE & 0.008 & 0.002 & $(0.004,0.013)$ & & \\
\hline \multicolumn{6}{|c|}{ Model 2 - perceptions of dating infidelity as dependent variable } \\
\hline GR & -0.124 & 0.077 & $(-0.275,0.027)$ & \multirow{3}{*}{0.076} & \multirow{3}{*}{$0.001 * *$} \\
\hline AGE & -0.062 & 0.014 & $(-0.090,-0.034)$ & & \\
\hline EXP x GR & 0.009 & 0.003 & $(0.004,0.014)$ & & \\
\hline \multicolumn{6}{|c|}{ Model 3 - perceptions of dating infidelity as dependent variable } \\
\hline NSE & 0.798 & 0.257 & $(0.292,1.304)$ & \multirow{3}{*}{0.070} & \multirow{3}{*}{$0.024 *$} \\
\hline GENDER & 2.814 & 1.178 & $(0.492,5.135)$ & & \\
\hline DCP $\times$ NSE & -0.461 & 0.202 & $(-0.860,-0.062)$ & & \\
\hline
\end{tabular}




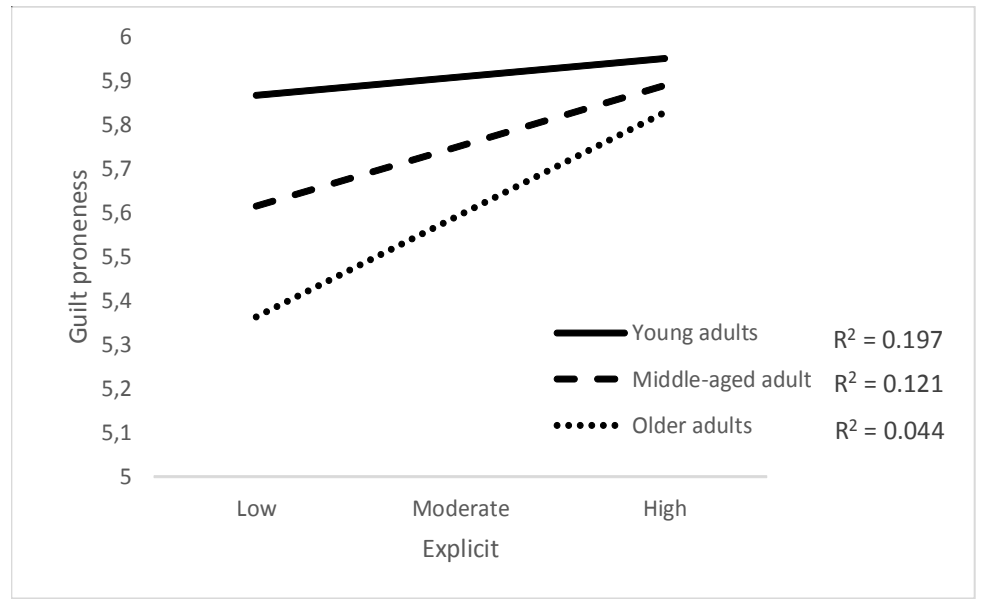

Figure 1 Moderation effect of age in the relationship between explicit and guilt-proneness.

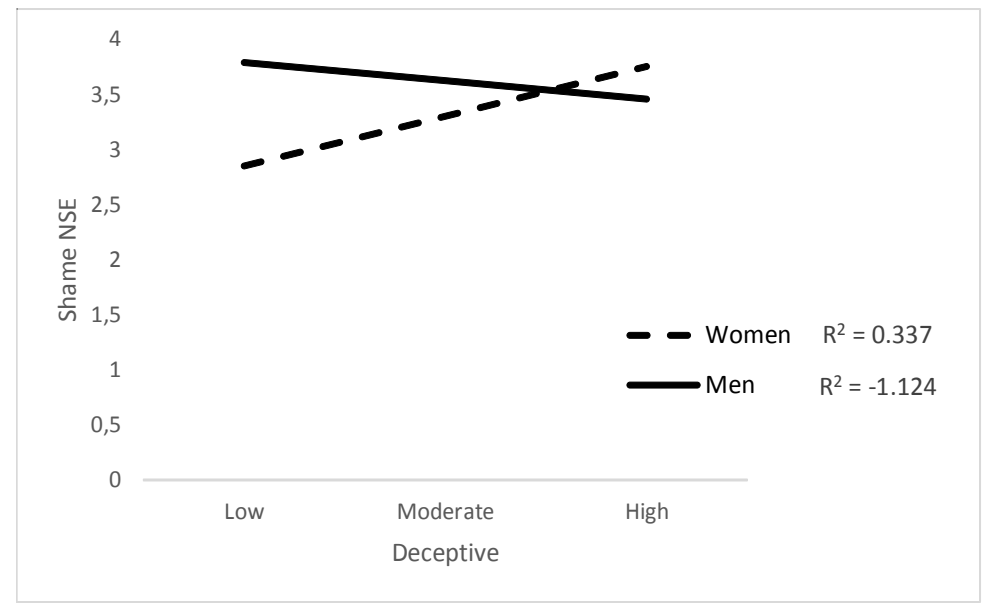

Figure 2 Moderation effect of gender in the relationship between deceptive and shame NSE. 


\section{Discussion}

The first contribution of our study was a discovery of a significant positive relationship between guilt-proneness and less permissive perceptions of emotional and sexual infidelity, which confirmed our hypothesis. Presented findings are consistent with a previous study by Wilson et al. (2011), who found that participants who reported less lenient perceptions of both types of infidelity reported a more frequent feeling of guilt than what they imagined when first engaging in extradyadic behaviors. Furthermore, Stuewig, Tangney, Mashek, Forkner, and Dearing (2009) found that guilt-proneness was significantly negatively associated with the number of sexual partners and risky sexual behaviors. In later longitudinal study, Stuewig, Tangney, Folk and Dearing (2014) found that children being identified with higher guilt-proneness at the fifth grade were less likely to have unprotected sex and were more likely to use birth control pills as teens. At the age of 18-21, they were reported to have fewer sexual partners.

There are several possible ways to explain our findings regarding guilt-proneness. First, both subscales of guilt-proneness in previous studies were found to have a modest inverse relationship with making unethical decisions (Cohen et al., 2011; 2012). Generally, infidelity involves morality issues. It is considered unethical; but extradyadic behaviors are less clearly defined as right or wrong (Selterman \& Koleva, 2015). Second, some studies show a significant to moderately strong correlation between honesty-humility and both subscales of guilt-proneness (Cohen et al., 2011; 2012b; 2014). Lacking honesty in an intimate relationship may create dubious and ambiguous circumstances and cases, where either partner may engage in extradyadic behaviors, which often lead to cheating. Here, honesty is important for preventing a partner from continuous cheating on the other. Third, there is a link between guiltproneness, conscientiousness, and infidelity. Previous research has clearly shown that higher conscientiousness is significantly related to weaker susceptibility to infidelity, as cited in a large review of personality factors' influence on infidelity by Jia, Ing, and Chin (2016). Moreover, various studies have found an existing significant to modest relationship between conscientiousness and guilt-proneness (Cohen et al., 2011; 2014; Fayard, Roberts, Robins, \& Watson, 2012). The aforementioned results suggest that people with higher guilt-proneness tend to be more honest, make fewer unethical decisions, and are more conscientious; this in turn results in having less permissive perceptions of dating infidelity. Interestingly, among all three types of extradyadic behaviors, guiltproneness has the strongest relationship with perceptions of deceptive behaviors (lying to the partner/withholding information).

In current research, despite the overall likeability of theme-infidelity among researchers, there has not been a single study showing the evidence of its significant association with shame-proneness. Although there exist some studies by Stuewig et al. (2009; 2014), these have focused only on the risk factors for later infidelity among high-schoolers. However, in these two longitudinal studies, shame-proneness did not correlate with considered risk factors for eventual susceptibility to infidelity later in young adulthood. Our study is thus the first that has shown a significant relationship between shame-proneness and attitudes towards infidelity; higher shame-prone participants attained a significantly higher score on both subscales of perceptions of emotional infidelity, which reflects less permissive attitudes toward specific extradyadic behaviors. However, regarding perceptions of sexual infidelity, only negative self-evaluations were significantly associated. We can speculate why shame with- 
drawal tendencies in our study were not related to permissive attitudes toward sexual infidelity.

In comparison with permissive perceptions of emotional infidelity, permissive perceptions of sexual infidelity appear to be more closely involved with decision making of unclear morality and dishonesty. Making an unethical decision is more constrained in shame-prone people with negative self-evaluations, whereas individuals characterized with higher shamewithdrawal tendencies are, on the other hand, more open to unethical decisions and less honest (Cohen et al., 2011; Cohen, Panter, \& Turan, 2012b; Cohen, Panter, Turan, Morse, \& Kim, 2014).

The link between shame-proneness and less permissive perceptions of emotional infidelity can be supported by following mechanisms. Higher shame-proneness involves more interpersonal difficulties, which may lead to weaker opportunities to attract multiple sexual partners. This results in lowering chances to engage in both types of infidelity later (Stuewig \& Tangney, 2007). When a highly shame-prone and shy person enters an intimate relationship because of less general experience in relationships, they may perceive a romantic partner too valuable. Such a person usually feels less attractive, creates far less opportunities for intimate relationships, and the loss of the current relationship may have a much harder impact. These factors, as perceived in the mind of such individual, may result in less susceptibility to at least emotional infidelity, because such individuals might not want to risk a clash in their intimate relationship on account of getting too intimate with another person.

In need for a better discussion, we were concerned about the results of all the conducted moderation analyses. Regarding this, age was detected only as a significant moderator of the relationship between guilt-proneness and perceptions of sexual infidelity; this relationship turned out to be the weakest among young Slo- vak adults. Overall, young adults in our sample attained higher score on guilt-proneness than older adults. This is quite surprising, because this finding completely diverges from previous research (Orth, Robins, \& Soto, 2010; Tangney et al., 2011; Cohen et al., 2011). We do not have any plausible explanation of why guilt-proneness among Slovaks goes in the opposite direction than past research has clearly defined.

As seen in the first figure, the relationship between guilt-proneness and perceptions of sexual infidelity increases with age and is the highest among the group of older adults. However, in young adults, guilt-proneness remains strikingly high and unrelated to perceptions of sexual infidelity. Anticipation of feeling guilty among young adults does not predict how perceptions of sexual infidelity are going to be shaped over time. It may be concluded that perceptions of sexual infidelity among young adults may better reflect hidden cheating tendencies than a longer history of cheating on their past or present partners. The results provided by the first diagram make us contend that among middle-aged and older adults, guiltproneness has a stronger relationship with less permissive perceptions of sexual infidelity than among young adults. High guilt-prone middleaged and older adults tend to consider sexual behaviors with someone besides their partner as cheating to a greater extent than low guiltprone middle-aged and older adults. Therefore, lenient perceptions of sexual infidelity in these age groups appear to reflect more accurately the chances of cheating in the past. In this sense, with increasing age, there is a higher likelihood of feeling guilty following a hypothetical engagement in extradyadic sexual activities. As people mature, they tend to develop better sensitivity for anticipation of feeling guilty towards possible involvement in extradyadic sexual activities. Our findings indirectly indicate that with increasing age, guilt-proneness may be increasingly more related to history of 
sexual infidelity. Hence, we speculate that longterm sexual infidelity may have a cumulative repressive effect on guilt-proneness, as it creates dubious moral identity of the actor. We additionally argue that unrestricted sex drive among regularly cheating people might be related to a slight decrease in guilt-proneness in a long run. Although high sex drive did not correlate with guilt-proneness in a study by Gilliland, South, Carpenter, and Hardy (2011), their sample consisted of men characterized by hypersexual behavior of rather unsatisfied sex drive. This discernibly differs from adults whose sex drive is very high, but satisfied thanks to a larger history of cheating.

The second figure depicts that there is a major gender gap in negative self-evaluations of shame-proneness among participants with permissive perceptions of deceptive behavior. It may reflect a tendency of unfaithful men to fear that their deceptive behavior will be uncovered. Women generally know better what other people think and feel (Wacker, Bolte, \& Dziobek, 2017); they have better episodic verbal memory and remember personal experiences better than men (Herlitz \& Rehnman, 2008). Hence, women are thought to be better at uncovering their partner's lies and inconsistencies in behavior. If male infidelity tends to be more easily uncovered, then men happen to be proven unfaithful more often and hence feel shame more frequently. These feelings of shame, if experienced more regularly, may gradually lead to a harder impact on the self, due to shame-proneness. Although further research is needed, our results may mildly suggest that women are more likely to be cleverer at covering up their infidelity and fear less that their deceptive behaviors will be uncovered. This may boost their confidence and self-esteem to engage in further deceptive behaviors.

There are several missing aspects of our study that need to be pointed out. Although during collection of results we controlled for relationship status (single, in free relationship, in relationship, married, or divorced), we decided to concentrate on it in a future study, owing to the length of the expected results and discussion. Up-to-date research cited by Silva et al. (2017) shows that it is unclear if relationship status is related to attitudes toward infidelity, because previous studies concluded divergent results. Another missing aspect of our study may be examining the history of extradyadic behaviors or infidelity. Although there is evidence that prior history of infidelity leads to more permissive attitudes toward extradyadic behaviors (Martins et al., 2016, Moreno \& Kahumoku-Fessler, 2018), we decided to avoid enquiring about the history of infidelity for several reasons. First, since many participants were single or divorced, they could not have been asked about the degree of involvement in extradyadic behaviors during their current relationship, unlike in the recent study (e.g., Martins et al., 2016). Second, to obtain information about the history of participants' infidelity, a single question about being unfaithful in previous relationships (e.g., Martins et al., 2016) did not seem to be sufficient to address the history. Our specific data collection strategy was not suitable for enquiring about a more detailed history of infidelity, owing to potential ethical issues regarding highly sensitive information.

\section{Conclusion}

This study is the first that examined the relationship between guilt- and shame-proneness and perceptions of dating infidelity. Until today, it is the third study to have conducted moderation analysis with perceptions of dating infidelity. Results derived from a large sample size of different developmental stages will hopefully trigger future studies in exploring how guilt- and shame-proneness is intertwined with attitudes towards infidelity. Until now, besides the Big Five personality factors and the six-di- 
mensional model of human personality HEXACO, there exists a lack of research about personality traits associated with attitudes towards infidelity.

\section{References}

Allen, T. (2018). In covenant: A grounded theory exploration of what helps evangelical marriages recover after sexual infidelity by the husband. (Doctoral dissertation). Retrieved from https:// digitalcommons.liberty.edu/doctoral/1766.

Baumeister, R., Stillwell, A., \& Heatherton, T. (1994). Guilt: An interpersonal approach. Psychological Bulletin, 115(2), 243-267.

Barta, W., \& Kiene, S. (2005). Motivations for infidelity in heterosexual dating couples: The roles of gender, personality differences, and sociosexual orientation. Journal of Social and Personal Relationships, 22(3), 339-360.

Berman, M., \& Frazier, P. (2005). Relationship power and betrayal experience as predictors of reactions to infidelity. Personality and Social Psychology Bulletin, 31(12), 1617-1627.

Bland, J. M., \& Altman, D. G. (1995). Multiple significance tests: The Bonferroni method. BMJ. Clinical Research, 310(6973), 170.

Blow, A., \& Hartnett, K. (2005). Infidelity in committed relationships II: A substantive review. Journal of Marital and Family Therapy, 31(2), 217 233.

Carmody, P., \& Gordon, K. (2011). Offender variables: Unique predictors of benevolence, avoidance, and revenge? Personality and Individual Differences, 50(7), 1012-1017.

Cohen, T., Wolf, S., Panter, A., \& Insko, C. (2011). Introducing the GASP scale: A new measure of guilt and shame proneness. Journal of Personality and Social Psychology, 100(5), 947-966.

Cohen, T., Panter, A., \& Turan, N. (2012a). Predicting counterproductive work behavior from guilt proneness. Journal of Business Ethics, 114(1), 4553

Cohen, T., Panter, A., \& Turan, N. (2012b). Guilt proneness and moral character. Current Directions in Psychological Science, 21(5), 355-359.

Cohen, T., Panter, A., Turan, N., \& Morse, L. (2012). Workplace experiences and character traits: The WECT Project, 84(3), 582-593.

Cohen, T., Panter, A., Turan, N., Morse, L., \& Kim, Y. (2014). Moral character in the workplace. Journal of Personality and Social Psychology, 107(5), 943963.
Cuñas, A., \& Koval, S. (2018). Percepción de la infidelidad de adultos en el Área Metropolitana de Buenos Aires. Universitas Psychologica, 17(2), 19.

Davis, D., Shaver, P., \& Vernon, M. (2004). Attachment style and subjective motivations for sex. Personality and Social Psychology Bulletin, 30, 10761090.

Dickerson, S., Gruenewald, T., \& Kemeny, M. (2009). Psychobiological responses to social self threat: Functional or detrimental? Self and Identity, 8(2), 270-285.

Fayard, J., Roberts, B., Robins, R., \& Watson, D. (2012). Uncovering the affective core of conscientiousness: The role of self-conscious emotions. Journal of Personality, 80(1), 1-32.

Fisher, M., Voracek, M., Rekkas, V., \& Cox, A. (2008). Sex differences in feelings of guilt arising from infidelity. Evolutionary Psychology, 6(3), 436-446.

Fraley, C., \& Shaver, P. (1998). Airport separations: A naturalistic study of adult attachment dynamics in separating couples. Journal of Personality and Social Psychology, 75(5), 1198-1212.

Gilbert, P. (2001). Overcoming Depression. A step-bystep approach to gaining control over depression. 2nd ed. New York: Oxford University Press.

Gilliland, R., South, M., Carpenter, B., \& Hardy, S. (2011). The roles of shame and guilt in hypersexual behavior. Sexual Addiction \& Compulsivity. The Journal of Treatment \& Prevention, 18(1), 12-29.

Gross, C., \& Hansen, N. (2000). Clarifying the experience of shame: The role of attachment style, gender, and investment in relatedness. Personality and Individual Differences, 28(5), 897-907.

Gruber, D., Hansen, L., Soaper, K., \& Kivisto, A. (2014). The role of shame in general, intimate and sexual violence. In G. Lockhart (Ed.), Psychology of Shame: New Research (pp. 39-62). New York: Nova Science.

Hackathorn, J., Mattingly, B., Clark, E., \& Mattingly, M. (2011). Practicing what you preach: Infidelity attitudes as a predictor of fidelity. Current Psychology, 30(4), 299-311.

Hayes, A. (2018). Partial, conditional, and moderated moderated mediation: Quantification, inference, and interpretation. Communication Monographs, 85(1), 4-40.

Heflin. S. (2015). Attachment and shame coping style: A relationship mediates by fear of compassion. (Doctoral dissertation). Retrieved from https:// mospace.umsystem.edu/xmlui/bitstream/handle/ 10355/46440/HeflinAttShaCop.pdf? sequence $=1$.

Herlitz, A., \& Rehnman, J. (2008). Sex differences in episodic memory. Current Directions in Psychological Science, 17(1), 52-56. 
Jia, T., Ing, K., \& Chin, M. (2016). A review of personality factors on infidelity. Journal Psikologi Malaysia, 30(1), 126-141.

Jonason, P., Teicher, T., \& Schmitt, D. (2011). The TIPI's validity confirmed: Associations with sociosexuality and self-esteem. Individual Differences Research, 9(1), 52-60.

Kruger, D., Fisher, M., Edelstein, R., Chopik, W., Fitzgerald, C., \& Stout, S. (2013). Was that cheating? Perceptions vary by sex, attachment anxiety, and behavior. Evolutionary Psychology, 11(1), 159171.

Labrecque, L., \& Whisman, M. (2017). Attitudes toward and prevalence of extramarital sex and descriptions of extramarital partners in the 21 st century. Journal of Family Psychology, 31(7), 952-957.

Lee, K., Ashton, M., Wiltshire, J., Bourdage, J., Visser, B., \& Gallucci, A. (2013). Sex, power, and money: Prediction from the dark triad and honesty-humility. European Journal of Personality, 27(2), 169184.

Levine, E., Bitterly, T., Cohen., T., \& Schweitzer, M. (2018). Who is trustworthy? Predicting trustworthy intentions and behavior. Journal of Personality and Social Psychology, 115(3), 468-494.

Lopez, F., Gover, M., Leskela, J., Sauer, E., Schirmer, L., \& Wyssmann, J. (1997). Attachment styles, shame, guilt and collaborative problem-solving orientations. Personal Relationships, 4, 187-199.

Luo, S., Cartun, M., \& Snider, A. (2010). Assessing extradyadic behavior: A review, a new measure, and two new models. Personality and individual differences, 49(3), 155-163.

Martins, A., Pereira, M., Andrade, R., Dattilio, F. M., Narciso, I., \& Canavarro, M. (2016). Infidelity in dating relationships: Gender-specific correlates of face-to-face and online extradyadic involvement. Archives of Sexual Behavior, 45(1), 193-205.

Mattingly, B., Wilson, K., Clark, E., Bequette, A., \& Weidler, D. (2010). Foggy faithfulness: Relationship quality, religiosity, and the Perceptions of Dating Infidelity Scale in an adult sample. Journal of Family Issues, 31(11), 1465-1480.

McKibbin, W., Miner, E., Shackelford, T. K., Ehrke, A., \& Weekes-Shackelford, V. A. (2014). Men's mate retention varies with men's personality and their partner's personality. Personality and Individual Differences, 56(1), 62-67.

Mikulincer, M., \& Shaver, P. (2007). Attachment in adulthood, first edition: Structure, dynamics, and change. New York: The Guilford Press.

Mongeau, P., Hale, J., \& Alles, M. (1994). An experimental investigation of accounts and attributions following sexual infidelity. Communication Monographs, 61(4), 326-344.
Moreno, N., \& Kahumoku-Fessler, E. (2018). Understanding infidelity: How perceptions of infidelity behaviors vary by sex and one's own infidelity experiences. The American Journal of Family Therapy, 46(2), 107-121.

Ong, A., Poon, P., Sibya, S., \& Macapagal, E. (2014) Gender, adult attachment styles, and the tendency to commit dating infidelity: A mixed methods study. Phillippine Journal of Psychology, 47(11), 93116.

Orth, U., Robins, R., \& Soto, C. (2010). Tracking the trajectory of shame, guilt, and pride across the life span. Journal of Personality and Social Psychology, 99(6), 1061-1071.

O'Sullivan, L., \& Meyer-Bahlburg, H. (2003). African-American and Latina inner-city girls' reports of romantic and sexual development. Journal of Social and Personal Relationships, 20(2), 221-238.

Ramsey, E. (1988). From guilt through shame to AA: A self-reconciliation process. Alcoholism Treatment Quarterly, 4(2), 87-107.

Randall, H., \& Byers, E. (2003). What is sex? Students' definitions of having sex, sexual partner, and unfaithful sexual behavior. Canadian Journal of Human Sexuality, 12(2), 87-96.

Selterman, D., \& Koleva, S. (2015). Moral judgement of close relationship behaviors. Journal of Social and Personal Relationships, 32(7), 922-945.

Shackelford, T., Besser, A., \& Goetz, A. (2008). Personality, marital satisfaction, and probability of marital infidelity. Individual Differences Research, 6(1), 13-25.

Schmitt, D., Alcalay, L., Allik, J., Angleitner, A., Ault, L., Austers, I., et al., (2004). Patterns and universals of mate poaching across 53 nations: The effects of sex, culture, and personality on romantically attracting another person's partner. Journal of Personality and Social Psychology, 86(4), 560-584.

Silva, A., Saraiva, M., Albuquerque, P., \& Arantes, J. (2017). Relationship quality influences attitudes toward and perceptions of infidelity. Personal Relationships, 24(4), 718-728.

Spanier, G., \& Margolis, R. (1983). Marital separation and extramarital sexual behavior. The Journal of Sex Research, 19(1), 23-48.

Stewart, C. (2017). Attitudes, attachment styles, and gender: Implications on perceptions of infidelity. (Doctoral dissertation). Retrieved from https:// digitalscholarship.unlv.edu/cgi/viewcontent. cgi article $=4175 \&$ contex $\mathrm{t}=$ thesesdissertations .

Stuewig, J., \& Tangney, J. (2007). Shame and guilt in antisocial and risky behaviors. In J. Tracy, R. Robins, \& J. Tangney (Eds.), The self-conscious emotions: Theory and research (pp. 371-388). New York: The Guilford Press. 
Stuewig, J., Tangney, J., Mashek, D., Forkner, P., \& Dearing, R. (2009). The moral emotions, alcohol dependence, and HIV risk behavior in an incarcerated sample. Substance Use \& Misuse, 44(4), 449471.

Stuewig, J., Tangney, J., Folk, J., \& Dearing, R. (2014) Children's proneness to shame and guilt predict risky and illegal behaviors in young adulthood. Child Psychiatry and Human Development, 46(2), 217-227.

Tafoya, M., \& Spitzberg, B. (2007). The dark side of infidelity: Its nature, prevalence, and communicative functions. In: B. Spitzberg \& W. Cupach (Eds.), The dark side of interpersonal communication (2nd ed., pp. 201-242). New Jersey: Lawrence Erlbaum Associates.

Tangney, J., \& Dearing, R. (2002). Shame and Guilt. New York: Guilford.

Tangney, J., Stuewig, J., Mashek, D., \& Hastings, M. (2011). Assessing jail inmates' proneness to shame and guilt: Feeling bad about the behavior or the self? Criminal Justice and Behavior, 38(7), 710-734.

Toplu-Demirtas, E., \& Fincham, F. (2017). Dating in fidelity in Turkish couple: The role of attitudes and intentions. The Journal of Sex Research, 55(42), 111.

Wacker, R., Bolte, S., \& Dziobek, I. (2017). Women know better what other women think and feel: Gen- der effects on mindreading across the adult life span. Frontiers in Psychology, 8, 1-7.

Weeks, G., Fife, S., \& Peterson, C. (2016). Techniques for the couple therapist: Essential interventions from the experts. New York, NY: Routledge.

Wei, M., Shaffer, P., Young, S., \& Zakalik, R. (2005). Adult attachment, shame, depression, and loneliness: The mediation role of basic psychological needs satisfaction. Journal of Counseling Psychology, 54(4), 591-601.

Wheeler, G. (1997). Self and shame: A gestalt approach. Gestalt Review, 1(3), 221-224.

Whitty, M., \& Quigley, L. (2008). Emotional and sexual infidelity offline and in cyberspace. Journal of Marital and Family Therapy, 34(4), 461-468.

Widmer, E., \& Tras, J. (1998). Attitudes toward nonmarital sex in 24 countries. The Journal of Sex Research, 35(4), 349-358.

Wilson, K., Mattingly, B., Clark, E., Weidler, D., \& Bequette, A. (2011). The gray area: Exploring attitudes toward infidelity and the development of the Perceptions of Dating Infidelity Scale. Journal of Social Psychology, 151(1), 63-86.

Wolfinger, N. (2017). Institute for family studies. America's generation gap in extramarital sex. Retrieved from https://ifstudies.org/blog/americas-generation-gap-in-extramarital-sex. 